\title{
The Effective Mode of Ideological and Political Education in "Internet plus" Environment
}

\author{
Zhang Dong \\ Wuchang Shouyi University, Hubei Wuhan, 430064
}

Keywords: Ideological and political education; Internet plus

\begin{abstract}
Nowadays, with the rapid development of Internet technology, China has entered the "Internet plus" era. Influenced by the Internet, the content of ideological and political education will become more diversified. In this case, the traditional mode of ideological and political education must carry out the transformation, in order to adapt to the changing situation of "Internet plus" era in education. For the ideological and political education, the development opportunities brought by "Internet plus" era shall be seized to complete the transformation of the education system, in order to guarantee the effect of education.

With China's entry into the "Internet plus” era, China's education has also undergone rapid changes. Under such circumstances, the updating speed of teaching content has become faster and the teaching mode has been changing constantly. At the same time, as the educated students, there have been some new changes in "Internet plus" era. In this case, the ideological and political education must accelerate the transformation speed, so as to adapt to various changes of "Internet plus" under the background of the times, to further enhance the effect of ideological and political education. This paper analyzes the influence of problems in ideological and political education, and points out the effective mode of ideological and political education under the "Internet plus" environment.
\end{abstract}

\section{The Positive Impact of "Internet plus" on the Ideological and Political Education}

For a long time, the main body of Ideological and political teaching is educators. In the process of making teaching contents, educators have worked out the contents of Ideological and political education according to the training objectives and training plans that have been completed. However, due to the limited amount of information that the traditional paper media can accommodate, the source of teaching content is too single. Under such circumstances, how much teaching content students can accept depends entirely on Teachers' knowledge reserves and teaching level. Under such circumstances, students' knowledge is limited. But after as "Internet plus" era, vast amounts of information in the network. This problem has been largely the link. Because of the large and rapid information capacity of the network media, high quality teaching resources and teaching methods can be shared by educators throughout the country in the shortest possible time. Under such circumstances, the content of Ideological and political teaching in schools has become more diversified. In this case, the ideological and political education of the school can jump out of the stereotype of the traditional teaching mode and gain a greater degree of development, which is also an important manifestation of the ideological and political education in the new situation [1].

With the rapid development of Internet technology, contemporary students are becoming more independent and independent. Under such circumstances, when they choose teaching methods, they rely more on their subjective judgement. In the ideological and political education, the traditional teaching mode is that teachers impart knowledge to students passively. In the actual teaching activities, many factors due to the limitation of traditional teaching methods, the teaching effect in the "Internet plus" era is very difficult to be guaranteed. It is precisely because of this, it is imperative to reform the teaching method of Ideological and political in the "Internet plus" era. With the rapid development of Internet information technology, not only the traditional way of 
Ideological and political teaching is changing quietly, but the new teaching methods are also emerging. Under such circumstances, the way of Ideological and political education has become more intuitive and open. The exchange and interaction between teachers and students are more than ever. Under such circumstances, the dominant position of students in classroom teaching has been reflected more and more. In addition, influenced by the Internet, the methods of Ideological and political education have become more diverse, which also makes the present ideological and political teaching work more dynamic [2].

To realize real education, to know whether it has achieved the desired effect, not only needs to refer to the frequency of communication and interaction between teachers and students, but also the more important reference index is the emotional communication between teachers and students. Nowadays, with the rapid development of network technology, students are more dependent on the Internet in their daily life and in their studies. Under such circumstances, the gap between school and society is being broken by the Internet. Because of the incomparable timeliness of network information, teachers can understand the true thoughts and needs of students through the Internet communication for the first time. Because of the timeliness of communication, teachers can help and guide students in a more timely manner. Compared with the communication in the classroom, the communication between teachers and students in the virtual network can be more effective in removing the estrangement between each other, so that the communication between the two sides is more in-depth, and the effect of communication is better. Under such circumstances, students are more likely to have faith in teachers. And after the establishment of the most basic trust between teachers and students, teachers and students can carry on more in-depth and sincere communication, and on this basis, ideological and political education will also receive better results.

\section{Some Problems in the Ideological and Political Education in China at this Stage}

Compared with the traditional paper media, the Internet is undoubtedly more inclusive and open. In the Internet world, different cultures, ideologies, regions and ideologies interact with each other and inevitably encounter various conflicts. In this case, the information on the network is unavoidable, and the ordinary students are difficult to identify their authenticity and advantages and disadvantages. In addition, some of the garbage information on the Internet often has an attractive appearance, and students will inevitably be affected by the bad information when they browse the network information. The values embodied in Internet culture are not only positive but also vulgar and rotten. Under such circumstances, students' world outlook is difficult to avoid interference from various bad factors. On this basis, in order to carry out ideological and political education work, first of all, we must correct the students' Outlook on world, life and values, which undoubtedly increases the difficulty of education. In addition, some teachers have realized that the Internet may have a very negative impact on the formation of students' values. However, the way to solve the problem is to force students to stay away from the Internet simply and rudely. In fact, in today's "Internet plus" era, because this method is very undesirable [3].

At this stage, the rapid development of Internet technology has provided countless conveniences for people's lives. For students, learning by using network is also an important way to improve learning efficiency. However, at present, some students in China have been overdependent on the Internet. With the popularity of smart phones and tablet computers, this dependence has become more serious, to some extent, it can even be called "Internet addiction". Specifically, students' dependence on the Internet can be divided into two types. First of all, with the popularity of smart phones and 4G networks, many students are addicted to using mobile phones to read novels, watch videos and play online games. And some students have their own smart phones, this problem is more serious. Secondly, the main purpose of some students to use the Internet is really learning. However, the virtual and convenient nature of the network has led to its increasing dependence on the Internet. Once they leave the network and resume learning in traditional ways, they often become confused. For students, no matter what the purpose of the network is, excessive indulgence will not only lead to a decline in their interpersonal skills, but also lead to myopia and harm the physical and mental health of the students. 
Today, with the rapid development of wow high tech, ideological and political teachers must transform the traditional education and teaching methods to meet the students' needs for knowledge in the new situation. In the present, although most teachers have seen the influence of the Internet on the traditional educational model, and a consensus has been reached on the effective use of the Internet in teaching, there are still a few good ways to combine teaching with the Internet in practical teaching, and the network technology related to teaching is still still in place. In the primary stage of development. At the present stage, because of the popularity of the network, students can obtain information that they need from various channels. Some information has even exceeded the needs of classroom teaching. In the process of obtaining information, students' values and knowledge structure will inevitably be impacted. Under such circumstances, if the traditional mode of Ideological and political education can not speed up the transformation, it will gradually fade behind in the teaching of the Internet age [4].

\section{Effective Mode of Ideological and Political Education under the "Internet plus" Environment}

In the "Internet plus" era, to guarantee the effect of Ideological and political education, it must be clear in the teaching of the subject position of the students. For the teachers in the new situation, the teaching activities are no longer instilling knowledge passively to the students, but providing education "service" and "product" for students, so that students can participate more actively in the teaching process, and enjoy the high quality teaching resources in the network in this process. In the course of teaching, teachers must make use of current news and social hot issues to find out the breakthrough point of teaching, and use the network to communicate with students actively, so as to increase the sense of the time of teaching content and the enthusiasm of students to participate in information. In addition, compared with other subjects, the process of Ideological and political education is not only limited to the classroom, but also in extracurricular time teachers can also communicate with students in the form of network and other forms of communication. In this process, the students can more effectively connect the ideological and political theory with the actual life, so as to deepen the impression of knowledge and promote the further improvement of the teaching effect [5].

For most students, the content of Ideological and political education is boring, and it is difficult to arouse interest in learning. Under such circumstances, teachers must improve traditional teaching contents. In the "Internet plus" era, with the application of the Internet more and more widely in teaching, teachers in the teaching process must follow the network information dissemination rules, combined with the actual situation of students learning the reasonable arrangement of teaching content. In particular, first of all, teachers need to defragment and flattened the traditional teaching content, and strengthen communication and communication with students through the network after the teaching process and the completion of a stage of teaching tasks. Secondly, in the course of teaching, teachers should make a thorough analysis of the students' ideas and ideas, regardless of their value orientation, and point out the advantages and disadvantages of their ideas or ideas, and guide the values of students to the right direction in the process of communication. Finally, conditional schools should increase for the development of the network teaching software investment, and combined with the actual situation of the students for the development of the University's teaching software, to provide more effective help to "Internet plus" era of Ideological and political education work.

As China entered the "Internet plus" era, with the ideological and political teachers' teaching level is more necessary to enhance. In this process, teachers must constantly update their ideas and thinking, and at the same time to optimize and upgrade their knowledge structure, so as to expand their vision. In addition, teachers must also improve their teaching methods, transform the traditional teaching method of simple sermon into the teaching method of communication and communication with students, and transfer the knowledge and truth of the teaching content to the students in a subtle way. In addition to communication in the classroom, teachers and students can interact with each other through social media. In the virtual network environment, students can 
often speak out and talk about their learning questions. Teachers can help students consolidate the knowledge they have learned while answering questions. In addition, with the development of new network media, in addition to the communication between teachers and students through social media, teachers can communicate more deeply through social media, such as communication, exchange of their own teaching experience and good teaching methods, and make progress in the process of communication [6].

In the "Internet plus" era, want to will work with the network technology and the ideological and political education organic, teachers and other relevant personnel need to pay great efforts. In this process, school leaders, teachers need to work together with "Internet plus" era of Ideological and political education reform and long-term planning. In this process, the parties concerned must unify their thinking and understanding. In the specific work arrangements, school leaders are mainly responsible for providing institutional and institutional guarantees and financial support, and integrate various teaching resources. In addition to the ability of Ideological and political teachers to use the ability of network technology to carry out effective training, and to the effect of teachers to participate in the training of appropriate incentives, so that the teaching work to adapt to the characteristics of the network age. As the main responsible for the teaching of teachers, in the "Internet plus" era, in addition to the ability to have certain of the application of network technology, must also actively explore the network technology and the ideological and political education combination method, and the practical application in the classroom teaching, so that the traditional ideological and political education with the Internet Network combined with further upgrading and development.

\section{Summary}

To sum up, with the "Internet plus" era, the ideological and political education in China has changed a lot. Specifically, these changes have both positive and negative aspects. Faced with such a situation, we must upgrade the current ideological and political education mode so as to ensure its teaching effect. The effective mode and the construction of "Ideological and political education Internet plus" environment, can from the aspects of teaching methods, teaching contents and teachers so as to reform and perfect, multi pronged approach, so as to promote China's ideological and political education to achieve further development.

\section{References}

[1] Bin L I. To Explore the Effective Strategies of Ideological and Political Education of College Students under the Age of Internet Plus[J]. Education Teaching Forum, 2016.

[2] Teng S S. On Ideological and Political Education of College Studentsunder the Background of “Internet Plus”[J]. Journal of Jincheng Institute of Technology, 2017.

[3] Zhang Q H, Marxism S O. Internet Plus the Minority College Students' Ideological and Political Education Innovation Mode[J]. Guizhou Ethnic Studies, 2017.

[4] Huang X M, Deng H Q, Yin W U, et al. Innovation Research on Ideological and Political Education in the "Internet plus" Era[J]. Journal of Hubei Correspondence University, 2017.

[5] Ding F. Analysis of the Ideological and Political Education of College Students under the Background of Internet Plus[J]. Theory Research, 2017.

[6] Yang F, University S R. To enhance the effectiveness of ideological and political education from the perspective of "Internet plus"[J]. Journal of Jiamusi Vocational Institute, 2017. 